Session TB4-4

\title{
Virtual microscope and spectrophotometer: Application to advanced placement biology and chemistry lessons
}

\author{
Sina Amini, Seung J. Lee, Charles S. Lessard and Kenith E. Meissner \\ Department of Biomedical Engineering \\ Texas A\&M University
}

\begin{abstract}
Instruments required for science labs are often beyond the budgetary scope of public schools, or are improperly maintained in working order. In addition, many experimental samples are either difficult or expensive to purchase. This limits the exposure of students in grades 6-12 to meaningful science labs in biology, chemistry and physics. Virtual instruments address these problems by providing a realistic laboratory experience to help students understand both the basics of the instrumentation as well as how to operate the specific instruments. Additionally, the flexibility incorporated in these virtual instruments enable students to meet the learning goals for a range of established lesson plans. We have developed virtual instruments in National Instruments' LabVIEW programming environment and designed them to meet the needs of the Advanced Placement (AP) curriculum in Texas. At this time, two virtual instruments have been developed, virtual microscope (VScope) and virtual spectrophotometer (VSpec). The VScope serves as an interactive microscope emulator with the capabilities of a research grade microscope. The VScope has advanced features including various objective lens $(4 \mathrm{x}, 10 \mathrm{x}$, and 40x), xy stage controller, coarse and fine focus adjust, and a usercontrolled condenser. Images are taken from a high-end microscope to provide data for specific AP labs. The VSpec mimics an analog type spectrophotometer and has wavelength selector, zerocalibration, and max-calibration. In each case, students learn how to operate the instrument and acquire data while being allowed to make common mistakes. Here, we display the basic capabilities of each instrument and demonstrate how they can be utilized with specific AP lesson plans (e.g. Biology Lab 4, Chemistry Experiments 13 and 24). As a flexible, cost-effective means to enable AP Biology and Chemistry courses, these instruments are intended to expand the exposure of secondary school students to science and to increase the pool students interested pursuing engineering degrees.
\end{abstract}

\section{Introduction}

The Virtual Instruments are the product of collaboration among Texas A\&M, National Instruments (Austin, TX), Advanced Placement Strategies (Dallas, TX) and Laying the Foundation (Dallas, TX). These instruments have been created in the LabVIEW programming environment. How would a virtual microscope or virtual spectrophotometer help in AP chemistry or biology lesson plans? These instruments are software packages that are loaded on a PC (or Mac running Windows) and simulate real instruments. They have a visual interface specifically designed to look like physical instruments. Students “operate” them by using the mouse or track pad to click buttons and/or turn knobs.

The aim of the virtual instruments is to provide a realistic laboratory experience to AP students in schools that are unable to provide and/or maintain expensive laboratory equipment, or to complement existing physical instrumentation. Thus, the impact of laboratory centric, integrated instructional units is blunted by the fiscal cost of establishing, maintaining and expanding both the 
facilities as well as the human resources upon which the approach is based ${ }^{1-7}$ In such cases these virtual instruments could serve as substitutes for the real thing. In other cases, these instruments can be used in pre-labs to familiarize students with instrument operation before encountering the real instruments.

Virtual instrumentation leverages the extensive body of work on secondary science curricula by providing a means to implement laboratory-supported integrated learning. It also enables teacher training by providing both easy access to the necessary instrumentation as well as laboratory experiments for which samples have already been prepared. Finally, special needs of disabled students are often not met in traditional, physical instrument-based science laboratories ${ }^{9}$. Virtual instruments would be available to these students through standard or specially adapted computer interfaces. Thus, virtual instruments enable science education at the secondary school level by facilitating meaningful laboratory experiences. Such experiences can prepare the students for advanced study in science and engineering, and increase the overall pool of students interested in continuing studies at the university level ${ }^{10,11}$.

\section{Virtual Microscope and Virtual Spectrophotometer}

Both virtual instruments are implemented in National Instruments' LabVIEW programming environment and the NI-Vision toolkit. LabVIEW provides a flexible development environment and is graphical user interface driven. NI-Vision facilitates fast image processing for realtime image display on the virtual microscope. Figure 1 shows the front panel display for each of the instruments. The instruments and associated samples are stored locally and samples may be added by putting the new data in the "local data files" folder under the main instrument (microscope or spectrophotometer) folder. The design makes the instruments expandable at the classroom level and capable of running on the relatively low-end computers found in secondary school classrooms.

The layout and features of the virtual microscope (Figure 1: left) resemble that of a basic research grade instrument. The realistic interface facilitates the students' learning experience by having them interact with a realistic replica of the physical instrumentation and makes the experience more than just a video game. Upon starting, the virtual microscope begins a sample loading utility that allows the user to select specific samples for the laboratory session from the larger sample collection. The instrument screen has an isometric view of the microscope with controls on the right and an eyepiece view screen on the left. Controls on the instrument include an on/off switch, xy stage with control knobs, illumination intensity adjustment, condenser with adjustment, fine/coarse focus adjust and objective selection $(4 \mathrm{x}, 10 \mathrm{x}, 40 \mathrm{x})$. Additional features include image acquisition and storage for later use in the lab report, a basic guide to the controls, sample slide selector and an optional grid display in the eyepiece view screen. The sample data and virtual microscope operation are designed such that the entire area of the selected sample may be observed at all possible magnifications. Features are also included that allow students to make common mistakes as on a physical instrument: focus errors, a dusty cover slip and the ability to "break" the slide with the objective. These features contribute to the realism of the instrument and facilitate transfer of knowledge.

The layout and features of the virtual spectrophotometer (Figure 1: right) is based on a Spectronic 20 with digital display. Again, the realistic interface facilitates the students' learning experience by having them interact with a realistic replica of the physical instrumentation. Upon starting, the virtual spectrophotometer begins a sample loading utility that allows the user to select specific samples for the laboratory session from the larger sample collection. The display shows the front view of the instrument with digital displays of both the Transmittance (\%) and Absorbance. Controls 
included on the virtual spectrophotometer include open/close sample chamber door, open/close shutter, "Zero" adjust for background removal, "Max" (or gain) adjust to set the instrument range, and wavelength adjust with numeric display. There is also a cuvette view screen that shows the sample before it is inserted into the sample chamber. The user may choose a sample from the selection of loaded samples or mix multiple loaded samples to create a "custom sample" such as a series dilution. For experiments in which the absorbance of the samples varies with respect to time, the "Elapsed time" button can be used to view the sample at different times and read the corresponding absorbance and transmittance. For this instrument, students can make errors such as failing to calibrate the instrument with the cuvette and appropriate solvent, forgetting to close the sample chamber door, and not cleaning a dirty cuvette. For example if the sample cover is open, a constant amount of ambient light is added to the light transmitted through the sample. This results in an incorrect absorbance measurement. Finally, a small amount of random noise ( 5\%) has been added to the light source to simulate a real light source. This is accomplished by generating a time varying random number which is added to the light from the lamp incident upon the sample.
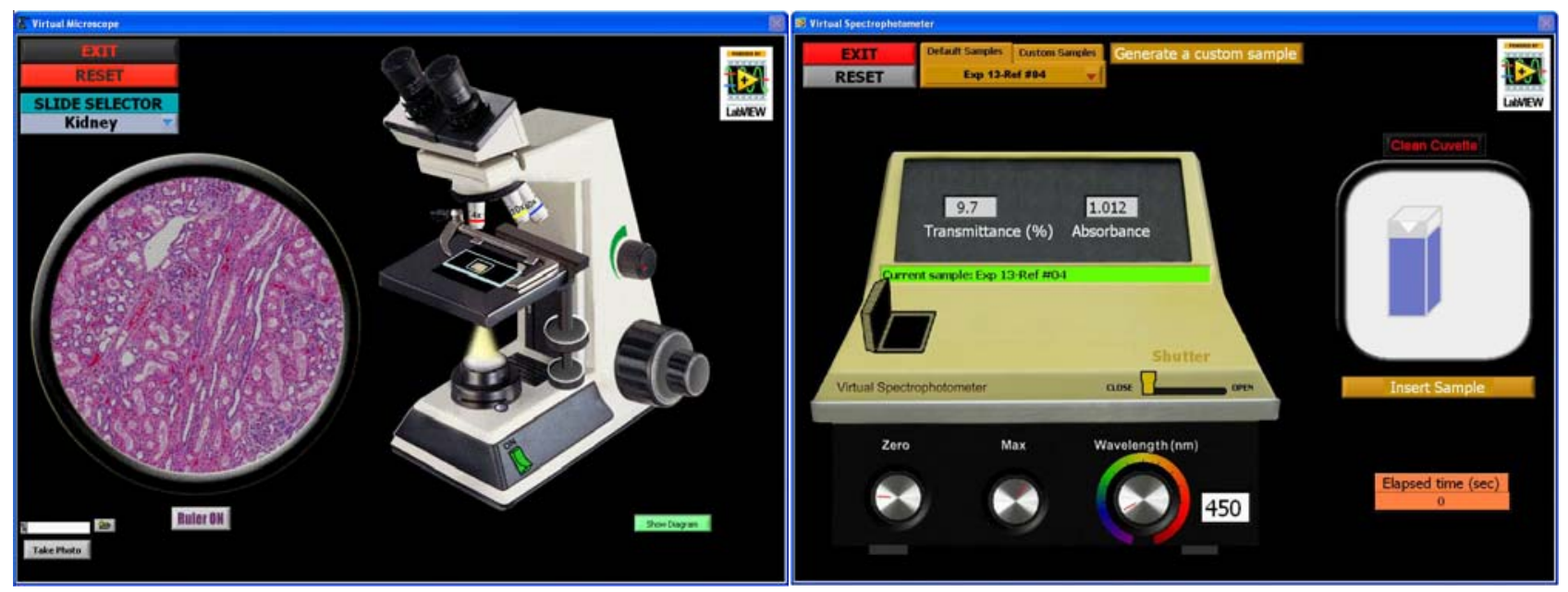

Figure 1: Virtual microscope (left) and virtual spectrophotometer (right)

The virtual instruments can be adapted to AP chemistry and biology experiments. For example in biology lab 4, "Plant pigments and photosynthesis", chemistry experiment 13, "The determination of $\mathrm{K}_{\text {eq }}$ for FeSCN" ${ }^{2+,}$, and experiment 24, "Preparation and analysis of Tetraamminecopper(II) Sulfate Monohydrate", the laboratory exercises call for the use of a spectrophotometer to measure the absorbance of samples at specific wavelengths. The virtual spectrophotometer with the appropriate samples can be used to provide the measurement portion of the laboratory exercise. These experiments have been implemented on the virtual spectrophotometer. In this paper the procedure and data obtained for experiment 13 are presented.

\section{Virtual Spectrophotometer: Advanced Placement Chemistry Experiment 13}

The purpose of this experiment is to determine equilibrium constant $\left(\mathrm{K}_{\mathrm{eq}}\right)$ in the equilibrium reaction of equation $1 . \mathrm{K}_{\text {eq }}$ for this reaction can be determined by equation $2^{12}$.

$$
\begin{gathered}
F e^{3+}(a q)+\operatorname{SCN}^{-}(e q) \leftrightarrow \mathrm{FeSCN}^{2+}(a q) \\
K_{e q}=\left[\mathrm{FeSCN}^{2+}\right] /\left[\mathrm{Fe}^{3+}\right]\left[\mathrm{SCN}^{-}\right]
\end{gathered}
$$


According to equation 2, to calculate the amount of $\mathrm{K}_{\text {eq }}$, known concentrations of $\mathrm{Fe}^{3+}$ and $\mathrm{SCN}^{-}$and measured concentration of $\mathrm{FeSCN}^{2+}$ should be used. To measure the concentration of $\left[\mathrm{FeSCN}^{2+}\right]$, a spectrophotometer is needed. In a spectrophotometer, light with a specific wavelength, $450 \mathrm{~nm}$, is passed through a sample and the amount of transmitted or absorbed light is measured. For students to be able to conduct the experiment with the virtual spectrophotometer, this data had to be collected on a physical spectrophotometer; the ten different solutions (five references and five test solutions) with specific amounts of Iron(III) Nitrate, $\mathrm{Fe}\left(\mathrm{No}_{3}\right)_{3}$, and Potassium Thiocyanate, $\mathrm{KSCN}$, were prepared and collected as depicted in Table 1 and Table $2^{12}$. The absorption spectra for both reference and test solutions are shown in Figure 2 and Figure 3, respectively.

Table 1: Reference solution contents

\begin{tabular}{|c|c|c|}
\hline Standard & $\begin{array}{c}\text { Volume of } 0.200 \mathrm{M} \\
\text { Fe(No })_{3} \text { solution }\end{array}$ & $\begin{array}{c}\text { Volume of } 0.00020 \mathrm{M} \\
\text { KSCN solution }\end{array}$ \\
\hline Reference solution \#1 & $8.0 \mathrm{~mL}$ & $2.0 \mathrm{~mL}$ \\
\hline Reference solution \#2 & $7.0 \mathrm{~mL}$ & $3.0 \mathrm{~mL}$ \\
\hline Reference solution \#3 & $6.0 \mathrm{~mL}$ & $4.0 \mathrm{~mL}$ \\
\hline Reference solution \#4 & $5.0 \mathrm{~mL}$ & $5.0 \mathrm{~mL}$ \\
\hline Reference solution \#5 & $4.0 \mathrm{~mL}$ & $6.0 \mathrm{~mL}$ \\
\hline
\end{tabular}

Table 2: Test solution contents

\begin{tabular}{|c|c|c|c|}
\hline Sample & $\begin{array}{c}\text { Volume of } 0.0020 \mathrm{M} \\
\text { Fe(No })_{3} \text { solution }\end{array}$ & $\begin{array}{c}\text { Volume of } 0.0020 \mathrm{M} \\
\text { KSCN solution }\end{array}$ & $\begin{array}{c}\text { Volume of } \\
\text { distilled water }\end{array}$ \\
\hline Test solution \#6 & $5.0 \mathrm{~mL}$ & $1.0 \mathrm{~mL}$ & $4.0 \mathrm{~mL}$ \\
\hline Test solution \#7 & $5.0 \mathrm{~mL}$ & $2.0 \mathrm{~mL}$ & $3.0 \mathrm{~mL}$ \\
\hline Test solution \#8 & $5.0 \mathrm{~mL}$ & $3.0 \mathrm{~mL}$ & $2.0 \mathrm{~mL}$ \\
\hline Test solution \#9 & $5.0 \mathrm{~mL}$ & $4.0 \mathrm{~mL}$ & $1.0 \mathrm{~mL}$ \\
\hline Test solution \#10 & $5.0 \mathrm{~mL}$ & $5.0 \mathrm{~mL}$ & $0 \mathrm{~mL}$ \\
\hline
\end{tabular}

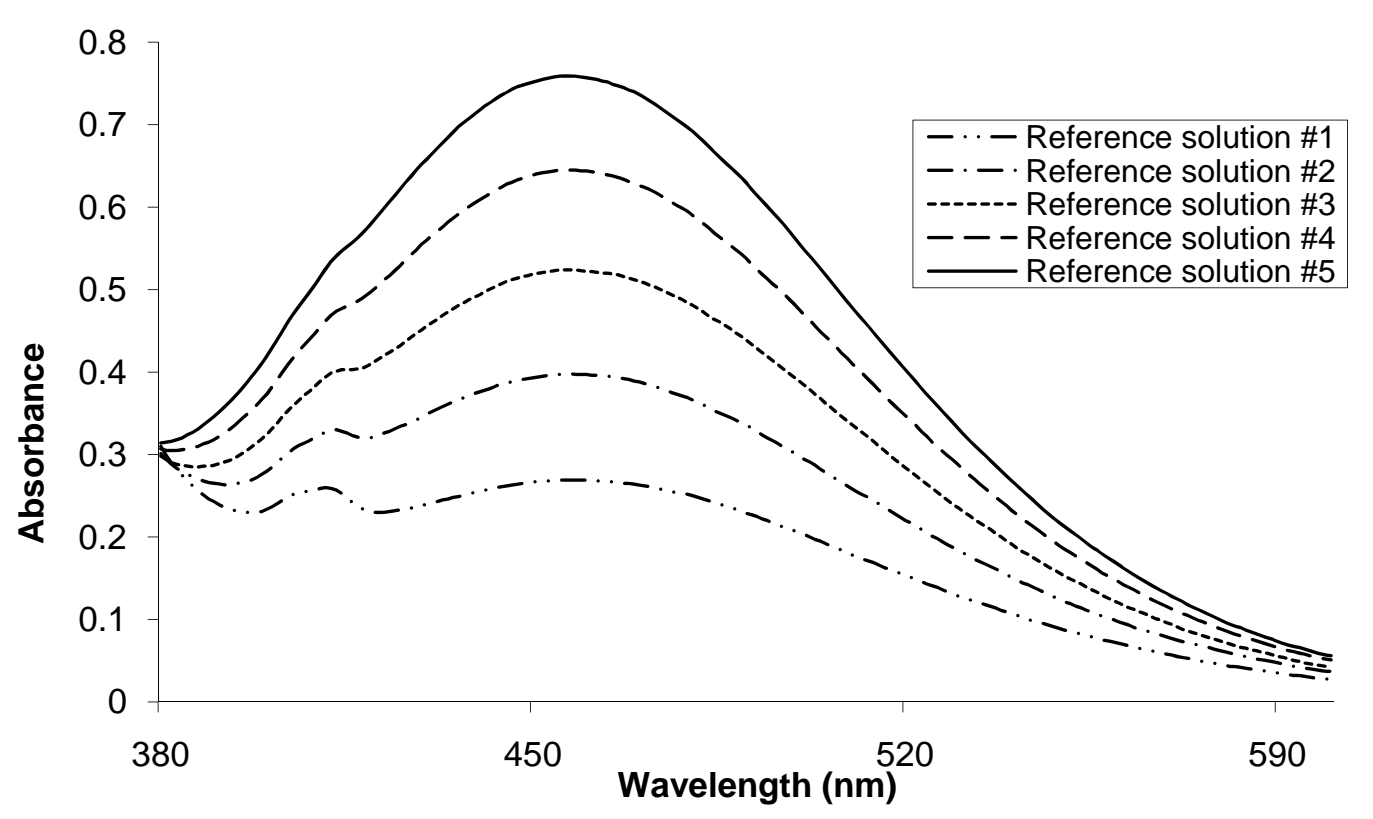

Figure 2: Absorbance curves for reference solutions 


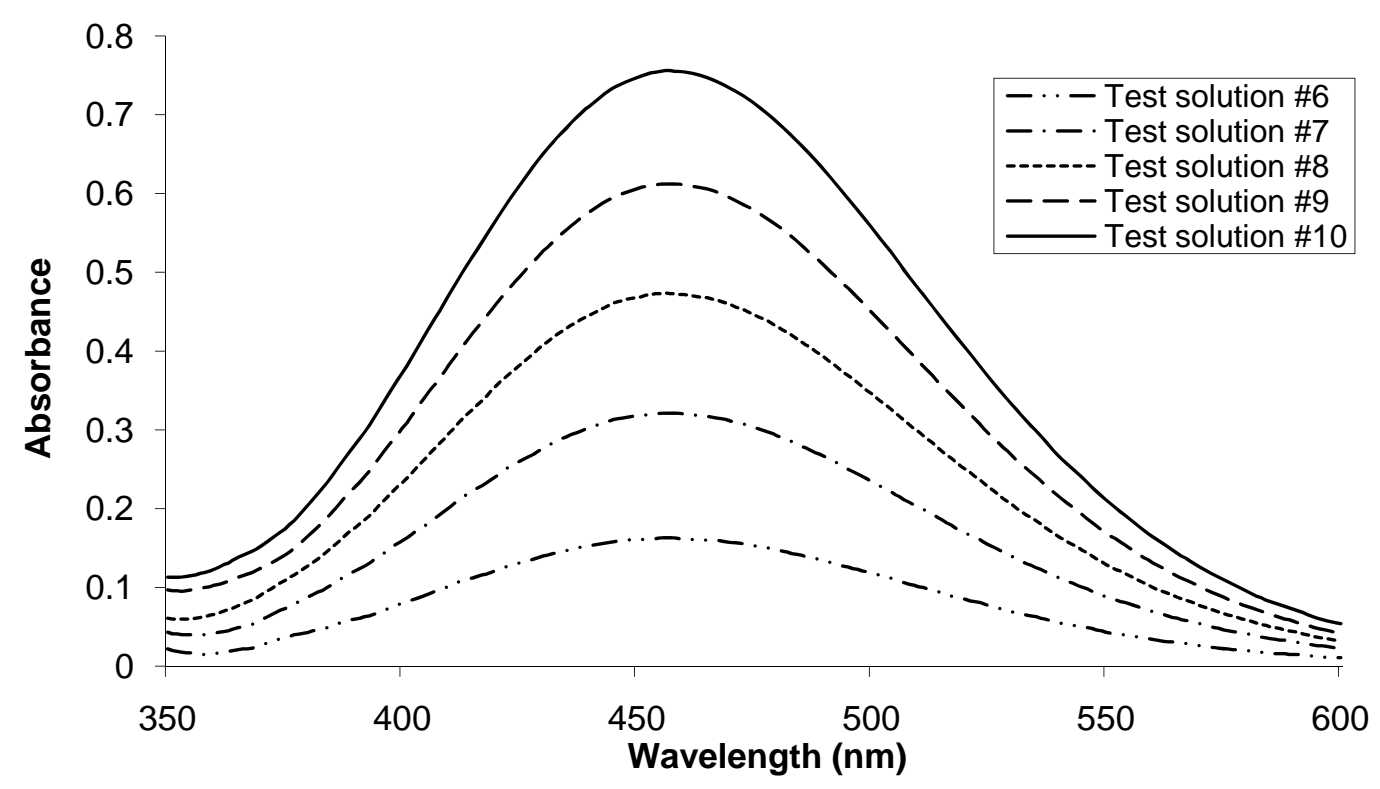

Figure 3: Absorbance curves for test solutions

These data are then implemented into sample files for the virtual spectrophotometer so that students can measure the absorbance of each sample at any wavelength in UV-VIS, including $450 \mathrm{~nm}$. The students may then construct the calibration curve by using reference solutions absorption. Finally, the unknown concentration of $\mathrm{FeSCN}^{2+}$ in test solutions can be calculated from the calibration curve by the aid of their absorbance values.

Once the samples have been constructed, they may be loaded into the virtual spectrophotometer for the experimental session. Figure 4 shows the sample loading page which appears when the virtual spectrophotometer program starts. The student chooses the desired samples from "Available Samples" and adds them to the "Loading List". By pressing "Load Samples and Start Program" button, the virtual spectrophotometer will be shown (Figure 5) and student will be able to start the experimental procedure.

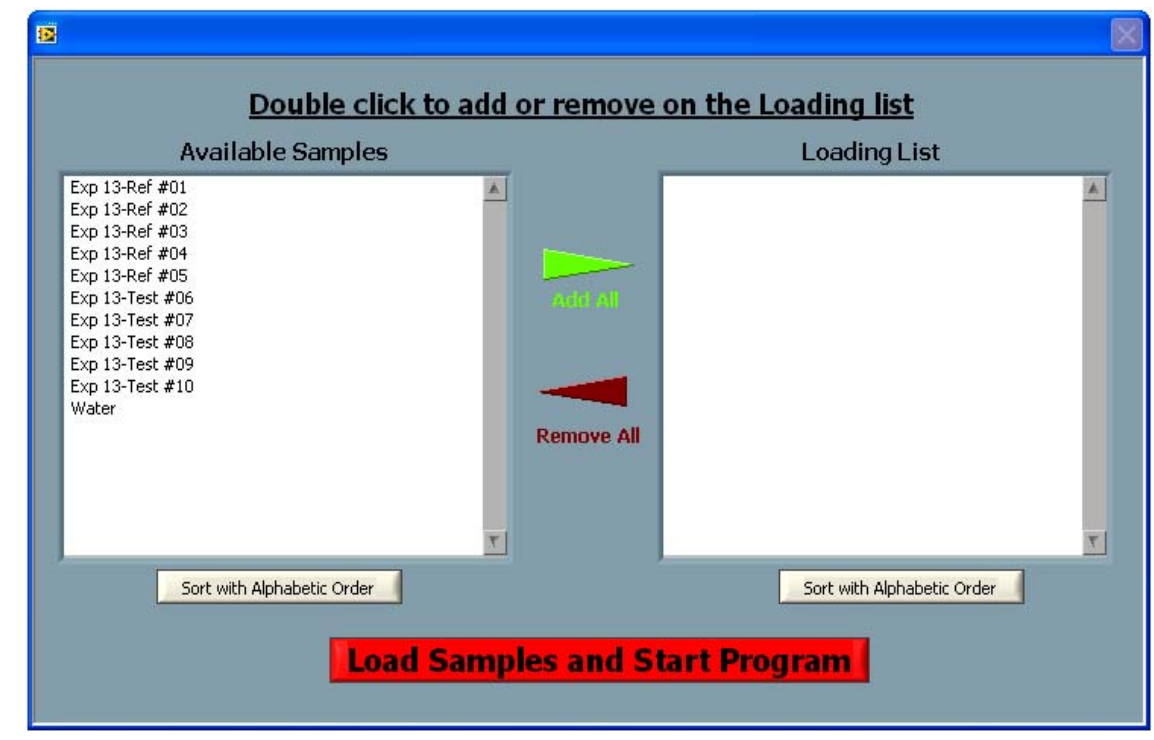

Figure 4: Sample loading page 


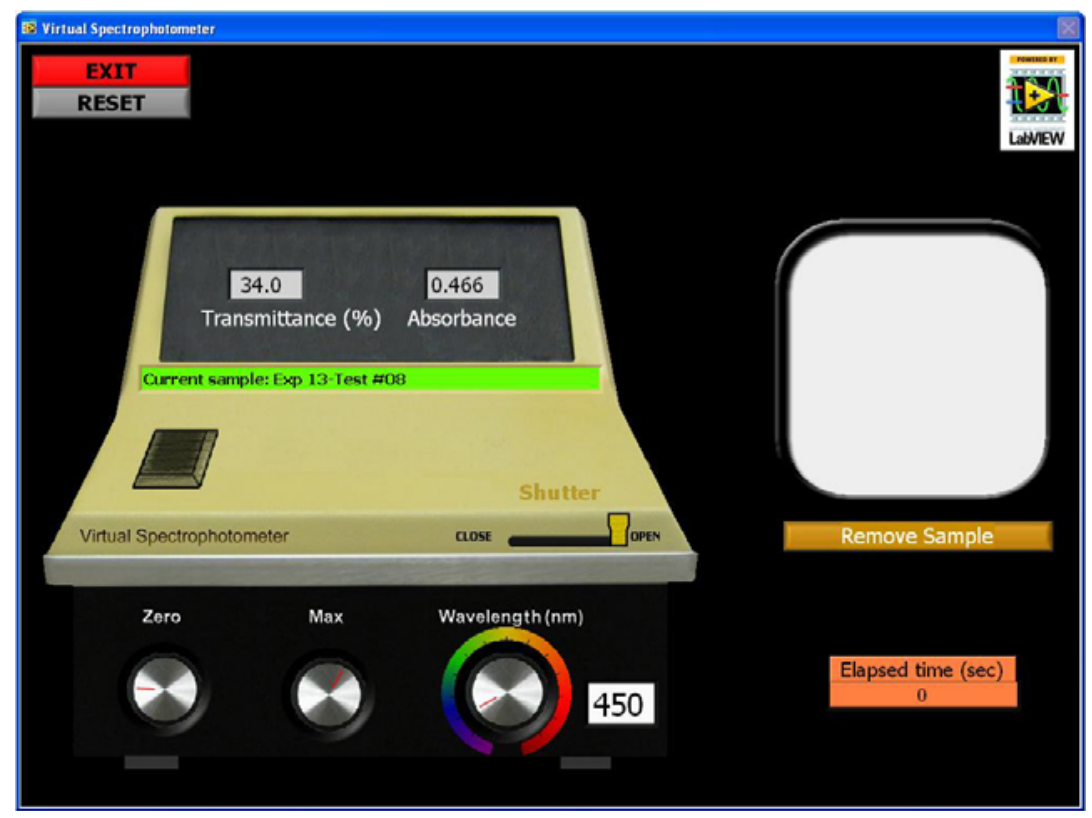

Figure 5: Virtual spectrophotometer

The experimental procedure follows that of the physical instrument. The student must:

- Set the desired wavelength, $450 \mathrm{~nm}$ in this case,

- Insert a cuvette with solvent (water) into the sample chamber,

- Close the sample chamber door,

- Adjust the "Zero" knob so the Transmittance reads 0\%,

- Open the shutter,

- Adjust the "Max" knob so the Transmittance reads 100\% and Absorbance reads 0.00

- Remove the "blank" sample and insert the desired sample,

- Close the sample chamber door,

- Record the data from the sample of interest.

Table 3 shows the measured absorbance of the solutions at $450 \mathrm{~nm}$ and the value that a student may read in the virtual spectrophotometer after calibration. Student data may vary because the noise has also been considered in the program.

Table 3: Absorbance in different solutions at $450 \mathrm{~nm}$

\begin{tabular}{|c|c|c|}
\hline Solution & Measured absorbance & Absorbance range in VI \\
\hline Reference solution \#1 & 0.267 & $0.264-0.269$ \\
\hline Reference solution \#2 & 0.393 & $0.390-0.395$ \\
\hline Reference solution \#3 & 0.519 & $0.516-0.521$ \\
\hline Reference solution \#4 & 0.639 & $0.636-0.641$ \\
\hline Reference solution \#5 & 0.752 & $0.749-0.754$ \\
\hline Test solution \#6 & 0.162 & $0.158-0.163$ \\
\hline Test solution \#7 & 0.318 & $0.315-0.320$ \\
\hline Test solution \#8 & 0.468 & $0.465-0.470$ \\
\hline Test solution \#9 & 0.606 & $0.603-0.608$ \\
\hline Test solution \#10 & 0.747 & $0.744-0.749$ \\
\hline
\end{tabular}




\section{Summary}

In this work, virtual microscope and virtual spectrophotometer have been designed to meet the needs of advanced placement curriculum. In addition to the discussed AP chemistry experiment 13, we have implemented AP chemistry experiment 24, and biology lab 4 data to the virtual instruments. These instruments are specifically designed to facilitate laboratory experiences in the case of limited or no access to physical instruments. In addition to providing sample data, the virtual instruments have been implemented with the details of physical instruments in order to provide students with a realistic laboratory experience. By allowing common mistakes and incorporating noise, students will get results which differ from the expected results. With this design, not only are students able to collect data with the virtual instruments, but they will also learn the basics of instrumentation and measurement. Because these instruments are designed to be standalone and operate on low-end computers, they can positively impact a wide range of students. AP chemistry experiment 13 was presented as an example of how these flexible instruments can be applied to existing course materials.

\section{References}

1. National Science Teachers Association Issue Brief, Science Teachers Speak Out: Laboratory Science, National Science Teachers Association, March 5, 2007.

2. Johnson, C. C., Kahle, J. B., Fargo, J. D., 2007, “A study of the effect of sustained, whole-school professional development on student achievement in science”, Journal of Research in Science Teaching, 2007, 44, pp. 775-786.

3. Lederman, N. G., 1999, "Teachers' understanding of the nature of science and classroom practice: Factors that facilitate or impede the relationship”, Journal of Research in Science Teaching 1999, 36, pp. 916-929.

4. Abramson, P., 9th annual school construction report, School planning and management, 2004.

5. The national survey of science and mathematics education: Trends from 1977 to 2000; Horizon Research: Chapel Hill, NC, 2002.

6. Public school facilities and teaching: Washington, DC and Chicago, 21st Century School Fund: Washington, D.C., 2002.

7. Analysis of data of the 2000 National Survey of Science and Mathematics Education for the committee on high school science laboratories: Role and vision, Horizon Research, Chapel Hill, NC, 2004.

8. Hofstein, A., Lunetta, V. N., 2004, "The Laboratory in Science Education: Foundations for the Twenty-First Century”, Science Education, 2004, 88, pp. 28-54.

9. Colwell, C., Scanlon, E., Cooper, M., 2002, "Using remote laboratories to extend access to science and engineering”, Compt. and Education, 2002, 38, pp. 65-76.

10. Fraser, B. J., Giddings, G. J., McRobbie, C. J., 1995, "Evolution and validation of a personal form of an instrument for assessing science laboratory classroom environments”, Journal of Research in Science Teaching, 1995, 32, pp. 399-422.

11. Wong, A. F. L., Fraser, B. J., "Cross-validation in Singapore of the science laboratory environment inventory. Psychological Reports, 1995, 76, pp. 907-911.

12. Flinn Scientific Inc., http://www.flinnsci.com

SINA AMINI

Mr. Amini is a PhD student in Biomedical Engineering Department at Texas A\&M University. He holds a bachelor and master's degree in Electrical Engineering. His research interests are in the areas of biomedical optics, biomedical imaging and biophotonics. He is currently a research assistant in Nanomaterials and Biophotonics Laboratory.

\section{SEUNG JOON LEE}

Dr. Lee is currently a postdoctoral research associate at Oak Ridge National Laboratory. He holds a bachelor's degree in Mechanical Engineering from Yonsei University (Korea) and both master's and doctoral degrees in Biomedical Engineering from Texas A\&M University. His current research interest is in biomedical instrumentation. 


\section{CHARLES S. LESSARD}

Dr. Lessard is an Associate Professor of Biomedical Engineering at Texas A\&M University in College Station, TX. He holds degrees in Electrical Engineering at the bachelor’s level from Texas A\&M University, at the master's level from The Air Force Institute of Technology and the doctoral level from Marquette University. He joined the faculty of Texas A\&M University after a 23 year military career that included flying F-86L interceptors and B-52 bombers, serving as Lead Engineer and Scientist with the School of Aerospace Medicine, and serving as Program Manager in the installation and testing of Spain's air defense system. Dr. Lessard specializes in physiological signal processing, design of virtual medical instrumentation, control systems, noninvasive physiological measurements, vital signs, nystagmus, sleep \& performance decrement, spatial disorientation, acceleration (G)-induced loss of consciousness (G-LOC) and neural network analysis.

\section{KENITH E. MEISSNER}

Dr. Meissner is an Assistant Professor of Biomedical Engineering at Texas A\&M University in College Station, TX. He earned his bachelor's degree in Electrical Engineering from Lehigh University and his Ph.D. in Optical Sciences from the University of Arizona. He served as a postdoctoral appointee at Sandia National Laboratory and spent five years in industry working on noninvasive glucose diagnostics. Before coming to Texas A\&M, Dr. Meissner spent four years as research faculty at Virginia Tech. His research interests are in biomedical optics, nanomaterials, microstructured sensors and energy transfer techniques. 